\title{
1 A functional trait approach reveals the effects of landscape context on ecosystem services
}

provided by urban birds

Timothy M. Swartz ${ }^{1, *}$, Jason M. Gleditsch ${ }^{1}$, and Jocelyn E. Behm ${ }^{1}$

${ }^{1}$ Integrative Ecology Lab, Center for Biodiversity, Department of Biology, Temple University, Philadelphia, PA 19140, USA

* timothy.swartz@temple.edu

Running Title Bird functional traits and ecosystem services

Keywords: response and effect traits, acoustic traits, aesthetic traits, cultural ecosystem services, fourth corner analysis, habitat management
Abstract
Land use intensification in urban areas can have profound effects on biological communities that provide valuable ecosystem services to urban residents. We used a functional response and effect trait approach to determine how bird species' responses to local and landscape-scale habitat of urban green spaces affects the supply of cultural and regulating ecosystem services. We sampled bird communities and habitat variables in urban green spaces that varied in local and landscape- scale habitat composition and compiled a dataset of species' response and effect traits related to nesting, foraging, diet, and visual and acoustic aesthetic appeal. Overall, the landscape-scale context of a green space had a stronger influence on species' abundances than local-scale habitat. Landscape-scale impervious surface surrounding our study sites interacted with response traits related to nesting in human-built structures, clutch size, and consumption of invertebrates to drive bird species' abundances. Because correlations between response and effect traits can influence the effect traits available to provide ecosystem services at a site, we explored the correlation of these three response traits to a suite of effect traits and found the response traits were correlated with several effect traits related to diet and regulating services but correlated with few of the plumage and acoustic traits that produce cultural services. Finally, we found that effect traits associated with cultural and regulating ecosystem services varied strongly along the landscape-scale gradient of urbanization. Sites with high impervious surface cover are expected to have low levels of invertebrate pest control and visual appeal but high levels of acoustic appeal, diet evenness (generalism), and granivory. Overall, our study highlights the key role of landscape-scale habitat in driving bird-mediated ecosystem services and underscores the importance of regional urban planning to create healthy and livable cities. 
Introduction

By 2030, $60 \%$ of the Earth's human population is expected to live in cities (United

37 Nations 2018) and global urban land area will have tripled from its 2000 baseline (Seto et al.

38 2011, Seto et al. 2012). In this context, it is increasingly important for the green spaces within

39 cities to provide a wide range of high-quality ecosystem services to urban residents (Young

40 2010, Aronson et al. 2017, Dickinson and Hobbs 2017). As such, understanding how the species

41 within urban green spaces generate ecosystem services has become a research priority (Ziter

42 2016, Schwarz et al. 2017).

43 Theoretically, the contribution of a particular species to an ecosystem service can be

44 predicted by its "effect traits" - attributes of a species that influence its effect on an ecosystem

45 service (Lavorel and Garnier 2002, Suding et al. 2008). When the relationships between effect

46 traits and ecosystem services are well-established, greenspaces can be managed to provide

47 particular ecosystem services by selecting species with optimal effect traits. This functional trait

48 approach has shown promise for urban green space and ecosystem service management. Plants

49 are typically the focus of these research efforts because strategic plantings can directly increase

50 the abundance of species with optimal effect traits (e.g., Tran et al. 2020, Kleyer 2021).

51 However, application of this functional trait approach to other organisms, like animals, which

52 also provide numerous ecosystem services (e.g., Whelan et al. 2008, Ghanem and Voigt 2012,

53 Valencia-Aguilar et al. 2013), poses distinct challenges since they cannot easily be introduced

54 directly into urban green spaces. Rather, ecosystem services provided by animals depend on

55 whether habitat characteristics within and around the green space attract and support species that

56 contribute to the service. As a result, "response traits" that affect a species' tolerance of 
57 environmental conditions (Lavorel and Garnier 2002, Suding et al. 2008) must also be

58 considered.

Species with response traits suited to habitat conditions are expected to be more abundant

60 in a particular locality (e.g., Cane et al. 2006, Luck et al. 2013, Pardo et al. 2018). Response

61 traits may interact with both local-scale habitat within a green space as well as a green space's

62 landscape-scale context (i.e., the habitat surrounding it). Local scale habitat suitability can

63 depend on attributes like vegetation structure and composition that relate to how green spaces are

64 managed (Aronson et al. 2017). The extent of suitable habitat in the landscape surrounding a

65 green space can also have a marked effect on species abundances within a greenspace (e.g., Blair

66 1996, Litteral and Shochat 2017). From a management perspective, it is particularly important to

67 determine the relative influence of local- versus landscape-scale habitat variables on the species

68 in a green space. If species respond more strongly to the landscape-scale variables that are

69 beyond a green space manager's jurisdiction, coordinated urban planning at a regional scale may

70 be necessary to augment biodiversity and the services it provides.

71 Consequently, the provisioning of ecosystem services in urban green spaces by animal

72 species is a result of correlations between species' response and effect traits. Species with the

73 optimal effect traits that provide desired ecosystem services will be abundant in a green space

74 only if they have response traits that allow them to tolerate the site's habitat conditions.

75 Relationships between response and effect traits will drive variation in effect trait distributions

76 across an urban landscape along gradients in the habitat variables to which species are

77 responding. As a result, due to their habitat conditions, green spaces may vary significantly in the

78 amount of ecosystem services they provide (Gardiner et al. 2013, Aronson et al. 2017). While

79 relationships between response and effect traits are predicted (Suding et al. 2008, Stachewicz et 
80 al. 2021), explorations of these relationships and their influence on effect trait variation in the

81 context of ecosystem service provisioning in urban landscapes are scant. Further, it is unknown

82 how these response-effect trait relationships vary for different types of ecosystem service.

83 Two important groups of ecosystem service in urban areas that involve animals are

84 regulating and cultural ecosystem services (Millennium Ecosystem Assessment 2005).

85 Regulating services, like seed dispersal and biological control of pests, tend to depend on effect

86 traits related to trophic position, foraging strategy, and morphology (Luck et al. 2012). Although

87 less well understood, animals also provide numerous cultural ecosystem services, which

88 encompass the diverse range of non-material benefits people derive from nature, like spiritual,

89 psychological, or recreation benefits (Millennium Ecosystem Assessment 2005). Effect traits

90 underlying cultural services include those that influence how humans perceive or interact with

91 species (Goodness et al. 2016, Echeverri et al. 2019a), such as traits relating to behavior and

92 aesthetic appeal. Cultural services can be particularly important in cities due to limited

93 opportunities for human-nature connections (Goodness et al. 2016, Dickinson and Hobbs 2017).

$94 \quad$ Here we use response and effect functional traits to examine how habitat conditions

95 impact the regulating and cultural ecosystem services provided by bird communities in urban

96 green spaces. Birds readily occupy habitats throughout the urban landscape (Blair 1996,

97 Callaghan et al. 2020) and are sufficiently well-studied that detailed trait data can be obtained

98 across a broad suite of response and effect traits (e.g., Wilman et al. 2014), from diet and

99 foraging behavior to plumage coloration and song characteristics. In turn, these traits link them

100 to a wide range of regulating and cultural ecosystem services (Sekercioglu 2006, Whelan et al.

101 2008, Echeverri et al. 2019a, Cameron et al. 2020). We identify the important response traits that

102 are driving variation in bird species abundances across local and landscape habitat variables. We 
103 then quantify response-effect trait correlations and explore how effect trait composition varies

104 with local and landscape habitat conditions. We conclude by modeling how the supply of

105 cultural and regulating ecosystem services may vary across urban green spaces due to these

106 habitat and trait relationships. Together, these analyses create an integrative approach exploring

107 how urban landscapes and green spaces can be managed for bird-mediated ecosystem services.

108 Methods

109 Study Region

110 We studied public urban green spaces in Philadelphia County, Pennsylvania, USA. As the sixth

111 most populous city in the United States (U.S. Census Bureau 2019), Philadelphia's green spaces

112 service a population of 1.58 million people. These green spaces consist of about 4,100 hectares

113 of public parks including plazas, playgrounds, sports fields, and forest preserves (Philadelphia

114 Parks \& Recreation 2021) as well as about 1,000 hectares of approximately 40,000 vacant lots

115 (Pearsall 2017, City of Philadelphia 2020). The Pennsylvania Horticultural Society has renovated

11612,000 of these vacant lots (South et al. 2018), which now function as supplemental public green

117 space in many neighborhoods (Heckert and Kondo 2018).

\section{Study Site Selection}

119 We measured bird communities and habitat at 60 sites in green spaces across the urban landscape

120 of Philadelphia (Table S1). We selected study sites to be distributed across two gradients

121 representing the availability of suitable habitat at the local and landscape scales (after Cox et al.

122 2018): 1) local scale tree canopy cover within the site boundaries and 2) landscape scale cover

123 of impervious surfaces, which includes roads, sidewalks, and buildings within a 500m radius

124 from the site centroid (Weaving et al. 2016). Both gradients were derived from a high-resolution

125 land cover raster (3m resolution; City of Philadelphia 2011) using ArcMap 10.7.1 (ESRI, 
126 Redlands, California, USA). Selected study sites were located $\geq 250 \mathrm{~m}$ from each other to limit

127 double-counting individual birds (after Ralph et al. 1995). The selected study sites were located

128 within green spaces ranging from small vacant lots $(0.05$ ha) to large forest preserves (e.g.,

129 Wissahickon valley park, 826 ha; Table S2).

130 Avian Point Counts

$131 \quad$ We sampled bird communities using 5-minute, 50m radius point counts at each site. All

132 birds seen or heard were counted and identified and their distance from the observer was

133 recorded with a laser range finder (Impact 850, Vortex Optics, Barneveld, WI). Counts were

134 conducted at the center of small sites $(<100 \mathrm{~m}$ across $)$ or at a random point $\geq 50 \mathrm{~m}$ from the edge

135 of larger sites. Sites were sampled during the breeding season of resident birds (May $21-$ July

13629,2019 ). To reduce bias caused by factors that influence the detectability of birds (Buckland et

137 al. 2012), all counts at all sites were conducted by a single observer (TMS) from 6:00 AM to

138 10:30 AM, when bird activity and detectability are highest (Rega-Brodsky and Nilon 2017) and

139 no counts took place during periods of precipitation or high wind. We sampled each site at two-

140 week intervals and varied the daily sampling order of sites. Each site was visited at least four

141 times, with 55 of the 60 sites being visited 5 times. We calculated site-level species abundances

142 as the mean number of individuals per species seen or heard across all sampling visits rounded

143 up to the nearest integer to accommodate use of 'fourth corner' analyses (see below).

\section{Landscape Context and Local Habitat Variables}

145 We measured landscape- and local-scale variables for each site to determine how they were

146 related to bird response traits. At the landscape scale, we measured landscape context based on

147 proportion of impervious surface cover (3m resolution; City of Philadelphia 2011) and tree

148 canopy cover ( $3 \mathrm{~m}$ resolution raster generated from the 2018 Philadelphia Tree Canopy 
Assessment; see O’Neil-Dunne 2019) within a 500m buffer radius of the avian sampling point in

ArcMap (Table 1). Other measures of landscape composition and configuration surrounding the

151 sites calculated with the R package landscapemetrics (Hesselbarth et al. 2019) were considered

152 for inclusion in the analysis but were highly correlated with the proportion of impervious surface

153 cover and were therefore excluded.

At the local scale, we assessed local habitat using field surveys of herbaceous and woody

155 vegetation composition and structure (Table 1) at each site. We modified the Breeding Biology

156 Research and Monitoring Database protocol (BBIRD; Martin et al. 1997) to measure woody

157 vegetation and used Daubenmire (Daubenmire 1959) methods to measure herbaceous vegetation.

158 There was substantial variation across sites in terms of the density and distribution of woody

159 vegetation (trees and shrubs), so we used two sampling methods. A "complete census" method

160 was used for sites $(\mathrm{N}=33)$ with sparse enough vegetation that all trees and shrubs could be

161 censused within a 100m radius from the bird point count location or within the site boundaries

162 for sites smaller than $100 \mathrm{~m}$ in radius. For sites with higher woody plant density $(\mathrm{N}=27)$ we used

163 a "census plot" method based on the BBIRD field protocol, which is designed for assessing

164 relatively homogenous habitats (Martin et al. 1997). For this method, woody vegetation was

165 assessed in four circular plots, with one plot centered on the point count location and three

166 located 10-30 m (depending on the size of the site) from the center point and evenly arranged at

$167120^{\circ}$ angles. The radius of the census plot was adjusted based on vegetation density to ensure

168 sampling efficiency (reduced from $10 \mathrm{~m}$ radius to $5 \mathrm{~m}$ radius in very dense shrubs; after Martin et

169 al. 1997). For both the complete census and census plot method, we recorded the identity of all

170 woody species, counted shrub stems, and measured the diameter at breast height (DBH) of all

171 trees $>1 \mathrm{~cm} \mathrm{DBH}$ within the whole site (complete census) or circular plot (census plot). We used 
172 counts of stems and tree DBH to calculate stem densities and basal area to use in subsequent

173 analyses.

Herbaceous vegetation (forbs and grasses) was sampled using a set of eight paired $0.5 \mathrm{~m}^{2}$

175 quadrats. A pair of quadrats was located within each of the four BBIRD plots in census plot sites

176 or their approximate location for complete census sites. In each quadrat, we visually estimated

177 the percent cover of grass (Daubenmire 1959) and recorded the height of the tallest stem of

178 herbaceous vegetation. The eight quadrat values were averaged for a site-level measurement for

179 each variable. Within each plot we also estimated tree canopy cover using a spherical

180 densiometer (Lemmon 1956) and averaged these four measurements for a site-level canopy

181 cover value.

182 Response and Effect Traits Acquisition

183 For each species observed during field sampling, we compiled a dataset of 16 response traits

184 related to how birds respond to environmental conditions and 14 effect traits related to regulating

185 and cultural ecosystem services (Table 2). We used response traits related to morphology (body

186 size and shape), diet composition, foraging stratum, and reproduction (nest location and clutch

187 size) (after Luck et al. 2012, Leveau 2013, Callaghan et al. 2019). For effect traits contributing to

188 cultural services, we used acoustic traits related to song complexity or variability, as well as bird

189 size, shape, and plumage color. For effect traits contributing to regulating services, we used diet

190 traits.

$191 \quad$ For all response and effect traits apart from acoustic traits, we obtained trait values from

192 the literature (sources detailed in Table 2). Due to the absence of published acoustic trait data, we

193 measured acoustic traits related to song variability and complexity in Raven Pro (v. 1.6.1, The

194 Cornell Lab of Ornithology, Ithaca, NY). Following Echeverri et al. (2019a), we selected a 
195 single representative recording for each species from the Xeno-Canto database (www.xeno-

196 canto.org). We selected recordings with low background noise, consisting of the primary song,

197 and recorded from southeastern Pennsylvania or the surrounding region, where possible

198 (Echeverri et al. 2019a). A call was used for species lacking song-type vocalizations $(\mathrm{N}=12)$.

199 The full list of recordings used is available in Table S3. For species with very large song

200 repertoires (e.g., Northern Mockingbird [Mimus polyglottus]), measurements were confined to a

201 representative $30 \mathrm{~s}$ clip. Two song characteristics were measured: number of syllables and total

202 song frequency range (Table 2). Research explicitly linking acoustic traits to human perception

203 of bird song aesthetics is scarce (Goodness et al. 2016), so we measured traits that capture the

204 variability and diversity of the pitch and syllables, which may reflect how acoustically interesting

205 and pleasant the songs are to human listeners (Echeverri et al. 2019a).

\section{Statistical Analyses}

207 We performed a series of analyses to link habitat and ecosystem services with response

208 and effect traits of bird species in urban green spaces. We provide an overview of our analytical

209 approach here with a detailed description of our methods to follow. We first identified response

210 traits and local and landscape habitat variables driving the abundances of bird species across our

211 study sites. We then determined whether any of these response traits were correlated with effect

212 traits that drive ecosystem service supply, suggesting a link between habitat variables and

213 ecosystem services. To explicitly examine the links between effect traits, habitat, and ecosystem

214 service supply at the community scale, we assessed how the summed effect traits in bird

215 communities varied with habitat variables. Then we assessed how ecosystem services calculated

216 from community-scale effect trait totals were influenced with habitat variables. All analyses 
217 were conducted in $\mathrm{R}$ ( $\mathrm{R}$ version 4.0.0; $\mathrm{R}$ Core Team 2015); code and data to replicate our

218 procedures are provided in Code S1 and Data S1.

219 Identifying key response traits and habitat variables

We identified the key response traits driving bird species' responses to habitat variables

221 using the "traitglm" function in the R package mvabund (Wang et al. 2012). This approach

222 models the abundance of species across multiple sites as a function of the species' traits,

223 environmental habitat variables, and the interaction between traits and habitat (Brown et al.

224 2014, Warton et al. 2015). The relative magnitude of the coefficients of the trait-habitat

225 interactions are an indicator of their importance in determining bird species abundances at sites

226 (Bartomeus et al. 2018) and are a way to identify the key response traits with respect to habitat

227 variables. Three matrices were used as inputs for this 'fourth-corner model' (see Legendre et al.

228 1997): 1) a site-by-species matrix of bird abundances at each of the 60 sites, 2) a species-by-trait

229 matrix consisting of the trait values for each species, and 3) a site-by-habitat matrix for

230 measurements of local- and landscape-scale variables. The landscape-scale variables were

231 percent cover of impervious surface and tree cover within 500m of our study sites. Local-scale

232 variables were the first two axes derived from a principal components analysis (PCA) performed

233 using the "rda" function from the vegan package in R (Oksanen et al. 2019) on our full set of

234 local habitat variables (see Table 1) to reduce the dimensionality of the data. These two axes

235 captured $52.02 \%$ of the variation in our local-scale variables and represent gradients of

236 vegetation density. Specifically, the first axis (PC1 - 34.82\% of variation) represents a gradient

237 in woody vegetation density from open lawn sites to natural, complex forest vegetation with high

238 shrub and large tree density. The second axis (PC2 - 17.2\%) represents a gradient of herbaceous 
vegetation density, from those with extensive bare ground to sites with unmown, overgrown

240 herbaceous vegetation (Fig. S1 \& S2).

We used the default negative binomial family and specified the "glm1path" method to

242 employ a LASSO penalty to perform model selection and reduce to zero the coefficients of trait-

243 habitat interactions that do not improve model fit as measured by the Bayesian Information

244 Criterion (Warton et al. 2015). We identified important response traits as those with standardized

245 interaction coefficients ranking in the $95^{\text {th }}$ percentile for absolute effect size and used these

246 important response traits in subsequent analyses.

247 Correlations between response and effect traits

248 Effect traits have no presumed relationship with habitat conditions (Suding et al. 2008).

249 Rather, habitat conditions impact ecosystem services via correlations between species' response

250 and effect traits. We investigated these relationships by testing for correlations between the

251 important response traits we identified and our 14 effect traits across all species observed in this

252 study using an abundance-weighted linear Pearson correlation (after Pakeman 2011). The mean

253 abundance of each species across all study sites was used for weighting. This allowed us to

254 account for the contribution of each species to the analysis in proportion to their abundance

255 across the whole data set. This procedure was performed with "weightedCorr" function from the

256 wCorr package (Emad and Bailey 2017).

257 Community-scale effect trait-habitat associations

258 The ecosystem services produced in a site depend on the entire community of service

259 providers (Suding et al. 2008). Accordingly, we used a redundancy analysis (RDA) to identify

260 associations between habitat variables and community-summed effect traits to determine how

261 effect traits vary across the urban landscape. RDA is a constrained ordination method that 
262 explains variation in community data using habitat variables (Ter Braak 1986, Borcard et al.

263 2018). Here, our community data consisted of a community-summed effect trait matrix where

264 effect trait values were multiplied by each species' site-level mean abundance then summed for

265 all species (see Table 2 for traits). These community-summed effect traits represent the total

266 amount of effect trait produced by the bird community at each site. The habitat data were a

267 matrix of the two local habitat PC axes (see Identifying key response traits and habitat variables

268 above) and the two landscape context variables (see Table 1 for variables). Community-summed

269 effect trait and habitat variables were mean-centered and scaled by the standard deviation. The

270 RDA was performed using the "rda" function in vegan (Oksanen et al. 2019). We used the

271 "anova.cca" function, also in vegan, to perform permutation tests of the significance of the

272 overall ordination and the significance of each RDA axis. An adjusted R-squared value was

273 generated with the "RsquareAdj" function as a measure of goodness of fit for the overall

274 ordination solution.

$275 \quad$ Modeling ecosystem service supply

276 To quantify how the habitat-effect trait associations scale to affect ecosystem services,

277 we used hypothesized trait-ecosystem service relationships to calculate seven ecosystem service

278 scores from the community-summed effect traits (after Tran et al. 2020; Table S4). In short, we

279 calculated simple additive measures for each effect trait family (visual, acoustic, and diet) by

280 summing the scaled values for each effect trait at each site, with each trait either contributing

281 positively or negatively to a service, based on the literature (Table S4). We generated linear

282 models to assess the relationship between the supply of each ecosystem service quantified from

283 the model and landscape scale impervious surface cover. We adjusted our alpha level to account

284 for multiple tests $(\mathrm{N}=7)$ using a Bonferroni correction (alpha $=0.007)$. 


\section{Results}

287 Across our 60 sites, 3,607 individuals from 45 bird species were observed and included in our 288 analyses. Mean site-level species richness was $8(\mathrm{SD}=3.5$, range $=2-21)$. The three most

289 common species, which comprised $66.7 \%$ of all individuals observed, were House Sparrow

290 (Passer domesticus; 38.5\%), European Starling (Sturnus vulgaris; 17.2\%), and American Robin

291 (Turdus migratorius; 11.0\%). The average site-level abundance of individuals per visit was 8.6

$292(\mathrm{SD}=5.4$, range $=1-52)$.

293 Identifying key response traits and habitat variables

Overall, trait-habitat interactions were stronger for landscape than for local habitat

295 variables; the average magnitude of interaction coefficients for response traits at the landscape

296 scale was 0.092 (range -0.172-0.176), which was nearly three times that of the interaction

297 coefficients for the local scale (0.034, range -0.05-0.085; Fig. 1). We identified three important

298 response traits with trait-habitat interactions in the $95^{\text {th }}$ percentile across all variables and each of

299 these response traits was associated with landscape-scale impervious surface cover. Species that

300 nest in human-built structures, species with smaller clutch sizes, and species with lower

301 proportion of invertebrates in their diets were more abundant in sites with higher landscape-scale

302 impervious surface cover (Fig. 1).

303 Correlations between response and effect traits

304 The abundance-weighted Pearson correlation showed that the three important response

305 traits we identified (i.e., invertebrate diet, clutch size, and nesting in built structures) were each

306 significantly correlated to several effect traits related to regulating and cultural ecosystem

307 services. (Fig. 2). Nesting in structures and invertebrate diet correlated with each of the diet 
308 effect traits, except diet evenness. Structure nesters were more likely to consume seeds rather

309 than invertebrates or fruits. Invertebrate consumers tended to also be fruit eaters and not seed

310 eaters. For cultural ecosystem service traits, response traits were only correlated to shape traits.

311 Species with larger clutches tended to be those with lesser body mass and longer bills and those

312 that nest in structures tend to have shorter tails.

313 Community-scale effect trait-habitat associations

314 Our ordination of site-level community-summed effect trait values revealed several links

315 between effect traits and habitat variables (Fig. 3). Overall, the explanatory local and landscape

316 habitat variables significantly captured variation in the effect traits $\left(\mathrm{F}_{4,55}=5.49, p<0.001 ; \operatorname{adj} \mathrm{R}^{2}\right.$

$317=0.23)$ and multicollinearity among explanatory habitat variables was low (VIF $<5$ for all).

318 Together, the habitat variables explained $28.55 \%$ of the total variance in community-summed

319 effect traits in our redundancy analysis (RDA). Permutation tests indicated that only the first

320 RDA axis explained a significant amount of variation in community-summed trait values

321 (RDA1: $\mathrm{F}_{1,55}=19.07, p<0.001 ; 24.78 \%$ of total variance explained) and the only explanatory

322 variable that had a significant relationship with RDA1 was impervious surface (i.e.,

323 Impervious_surf; RDA1: $\mathrm{F}_{1,55}=18.12, p<0.001$ ), which had a negative relationship with

324 RDA1. RDA2 explained substantially less variation in summed trait values and was not

325 significant $\left(\mathrm{F}_{1,55}=1.44, p=0.67 ; 1.87 \%\right)$.

326 For the most part, effect traits that contribute positively to the supply of plumage- and

327 shape-related aesthetic services (filled red and blue symbols in Fig. 3) were more prevalent at

328 sites with lower landscape impervious surface cover (positive relationship with RDA1) (Fig. 3).

329 In contrast, traits that supply acoustic services (filled yellow symbols) were more prevalent at

330 sites with high impervious surface cover (negative relationship with RDA1). For regulating 
331 services, relationships between community-summed effect traits and RDA1 varied by service,

332 with a negative relationship with RDA1 for granivory and diet evenness and a positive one for

333 invertivory.

$334 \quad$ Modeling ecosystem service supply

335 These relationships suggested by the RDA were also observed in our ecosystem service

336 scores (Fig. 4). Services associated with diet evenness, granivory, and acoustic aesthetics are

337 predicted to increase with impervious surface cover, whereas services related to invertivory,

338 plumage, and shape aesthetics are expected to decrease. Frugivory services did not strongly

339 correspond to impervious surface levels.

340 Discussion

341 In this study, we applied a functional trait approach to understand how the response of

342 bird species to local and landscape habitat characteristics shape the community-scale supply of

343 ecosystem services provided in urban green spaces. Most urban animals and their associated

344 services cannot easily be managed through direct introductions of species into green spaces.

345 Instead, we show how response and effect functional traits can be used to identify habitat

346 characteristics important for supporting urban bird communities that provide valued ecosystem

347 services for human well-being. Although all of our sites are located within the boundary of

348 Philadelphia's city limits, bird species still responded strongly to the habitat gradient generated

349 by land use intensification, which has implications for the provisioning of ecosystem services. In

350 our study, landscape-scale impervious surface cover influenced a range of functional traits and

351 thus affects the availability of both regulating and cultural ecosystem services provided by bird

352 communities. In light of the ongoing expansion and intensification of urban land cover (Seto et 
353 al. 2011, Seto et al. 2012), these findings have important ramifications for urban ecosystem

354 service management.

A major component of managing urban green spaces for ecosystem services entails

356 identifying interactions between habitat and species' response traits, since these interactions

357 affect the presence and abundance of potential service-providing species. Although the urban

358 green spaces we studied varied considerably in their local-scale habitat structure and

359 composition, the strongest trait-habitat interactions were observed for landscape-scale variables,

360 especially impervious surface cover. Thus, the scale at which green space management decisions

361 are made (local) may not match the scale at which bird communities respond to habitat

362 (landscape). The influence of landscape-context on urban bird diversity has been clear for some

363 time (Donnelly and Marzluff 2004, Luther et al. 2008), but local-scale habitat interventions

364 remain a key approach to green space management (Aronson et al. 2017). While beneficial to

365 urban bird conservation (e.g., Threlfall et al. 2017, Reynolds et al. 2019), these local-scale efforts

366 may have limited impact on ecosystem services that are affected by species' abundances. Some

367 green spaces surrounded by extensive impervious surface cover may simply be too small or

368 isolated to support sufficiently large populations of service providers. Local-scale efforts to

369 protect species of conservation concern should be coupled with landscape-scale planning to

370 address ecosystem service needs (Jokimäki et al. 2018, Liordos et al. 2021).

371 Strong correlations between response and effect traits are considered to render ecosystem

372 services vulnerable to environmental change (Suding et al. 2008, Stachewicz et al. 2021).

373 However, these correlations are crucial to managing habitat for ecosystem services. If effect

374 traits do not correlate with the response traits that interact with habitat to drive species

375 abundances, then effective, predictable habitat management will be elusive. Our abundance 
376 weighted response-effect trait correlation analysis revealed connections between response traits

377 and some, but not all, effect traits. For example, structure-nesting correlated with diet effect

378 traits, highlighting the direct connection between the proliferation of anthropogenic nest sites in

379 areas with high impervious surface cover and the supply of diet-based regulating services. In

380 contrast, only weak correlations were observed between response traits and plumage and

381 acoustic effect traits, leaving us without a firm explanation for the observed effect of impervious

382 surface on cultural services. It is possible that correlations between cultural effect traits and

383 response traits do not exist (Suding et al. 2008). However, it seems more likely that either

384 correlated response traits were not selected in the trait-habitat analysis, which identified a limited

385 subset of traits as important, or that correlated effect traits were not included in our analyses.

386 Investigation of effect traits related to cultural ecosystem services is a relatively new endeavor

387 (e.g., Echeverri et al. 2019a, Zoeller et al. 2020) that may reveal as yet unidentified effect traits

388 for which there are correlations. Until such relationships are known, predictable management of

389 cultural services through local and landscape-scale interventions may be difficult.

391 associations scale up to influence ecosystem services at the community scale. Landscape cover

392 of impervious surface was clearly associated with community-summed effect trait values for the

393 diet, plumage, and shape trait families. Notably, we found that the services that granivores could

394 provide, like the consumption of carbohydrate-rich littered food waste (Youngsteadt et al. 2015),

395 may be relatively high in sites with high landscape impervious surface cover. In contrast,

396 invertebrate pest control is likely low. In some respects, this pattern may match demand for such

397 services, with a higher need for litter removal in population-dense areas. However, invertebrate

398 pest outbreaks often occur in urban areas and isolated green spaces within a high impervious 
surface context may be more vulnerable to such outbreaks (Long and Frank 2020). Furthermore, despite particularly high demand for cultural ecosystem services in areas with more impervious

401 surface cover (Goodness et al. 2016, Valente-Neto et al. 2021), they are likely most scarce there

402 due to the absence of colorful species. By increasing natural cover in the landscape context

403 surrounding urban parks, managers may be able to attract more visually appealing species and

404 improve cultural service supply.

Our functional trait approach revealed that acoustic aesthetics may be one cultural ecosystem service that is generally higher in green spaces surrounded by high impervious surface land cover. While some abundant urban birds (including House Sparrow [Passer domesticus])

408 possess vocalizations consisting of simple, repeating syllables, European Starling (Sturnus

409 vulgaris), another species abundant in our study sites, has an extensive song repertoire,

410 counterbalancing the simple House Sparrow song in our community-scale analyses. Other

411 research approaches have shown contrasting results. In one of the few studies to explore the

412 influence of House Sparrow songs on human perception of the urban soundscape, not only were

413 their vocalizations found to be the least appealing but they reduced overall soundscape appeal

414 when their songs were added to a multi-species chorus (Hedblom et al. 2014). Given the current

415 paucity of research on the relationship between bird song and ecosystem services (Goodness et

416 al. 2016), this is an area where future study of the links between traits and human perception in

417 real-world contexts is warranted.

418 The need to understand how animal traits generate ecosystem services at a community-

419 scale applies to aesthetic traits and to cultural services more broadly. The links we have made

420 between visual and acoustic traits and the cultural services supplied by green space bird

421 communities are reasonable given present evidence (Goodness et al. 2016), but some are 
untested. We represented these relationships with unweighted additive models since existing research has focused on directionality of trait contributions to aesthetic appeal and on rankings of

424 appeal across species (Lišková and Frynta 2013, Lišková et al. 2015, Echeverri et al. 2019b).

425 Describing the relative importance of and interactions between different traits is needed to 426 develop more complex models. Such models must also account for the scale at which humans

427 experience birds (see Cox et al. 2017). For example, bird species with highly appealing traits that 428 are rare or difficult to observe may make an overall smaller contribution to ecosystem services

429 than less appealing species that are more abundant and gregarious, but these relationships likely

430 vary depending on the human observers involved (e.g., birdwatchers vs. non-birdwatchers;

431 Echeverri et al. 2019a). Research that builds on species-level studies of bird aesthetics to link

432 communities to cultural service supply (Hedblom et al. 2014), would greatly advance our

433 understanding of how global trends in urbanization and green space management will influence

434 the cultural services provided by urban birds.

In providing a step toward functional trait approaches to managing urban green spaces,

436 our study highlights several future avenues for investigation. First, we expect services to shift

437 with the temporal dynamics of bird communities (e.g., Leveau 2022) including the loss of

438 migratory breeding species in winter and the influx of transitory non-breeding migrants in spring

439 and fall (Graves et al. 2019). While breeding bird communities provide a constant supply of

440 cultural services to summer-time park visitors, non-breeding migrants may provide a strong

441 pulse of services over a short period. Additionally, birds are just one of many urban animal taxa

442 which provide ecosystem services. Other services and their associated communities, like

443 biological control by predatory arthropods (Burkman and Gardiner 2014, Gardiner et al. 2014) or

444 cultural benefits provided by charismatic butterflies (López-Hoffman et al. 2010), may be a more 
445 easily be managed through local-scale actions (i.e., mowing, tree planting, seeding native plants).

446 These opportunities should be investigated within a functional trait framework. Applying a trait-

447 based approach to other taxa and seasons would undoubtedly provide further insight into the

448 feasibility of managing local green space habitats for ecosystem services

449 Conclusion

$450 \quad$ Urban green spaces are a centerpiece in cities' efforts to create thriving urban landscapes.

451 In this endeavor, cities face a difficult task of balancing the demands placed on urban green

452 spaces to provide ecosystem services including carbon storage, urban heat mitigation, recreation,

453 psychological benefits, wildlife habitat, as well as space for cultural enrichment and social

454 interaction (Madureira and Andresen 2014, Aronson et al. 2017, Tran et al. 2020). Our goal here

455 has been to implement an approach using functional traits to quantify the relationships between

456 habitat and the service-providing organisms it supports. We suggest that if managers are

457 equipped with knowledge about community-scale functional responses to management actions,

458 they could pursue targeted interventions to augment desirable services. In this process, tradeoffs

459 among ecosystem services are likely (Haase et al. 2014, Dennis and James 2017) and the

460 decision-making process needs to account for the relative value of the various services in

461 question (Manning et al. 2018). Our approach offers a transparent way to address this challenge

462 by making relationships between habitat, functional traits, and services explicit. Careful,

463 community-engaged management is needed to ensure that green spaces and their biodiversity

464 continue to provide healthy, livable conditions for the world's growing population of urban

465 residents. 
bioRxiv preprint doi: https://doi.org/10.1101/2022 02.28 .482331 ; this version posted March 2, 2022. The copyright holder for this preprint

(which was not certified by peer review) is the author/funder, who has granted bioRxiv a license to display the preprint in perpetuity. It is made available under aCC-BY-NC-ND 4.0 International license.

\section{ACKNOWLEDGEMENTS}

467 We are grateful to Payton Phillips, Matthew Helmus, Nicholas Huron, Rachel Spigler, Amy

468 Freestone, and Brent Sewall for their feedback on earlier versions of this manuscript. We thank

469 Spencer Williams and Rachel Lewandowski for their tireless assistance in the field and Brendan

470 Pang and Kayla Perre for their contributions to the data cleaning and functional trait collation.

471 This work was funded by Temple University and TMS was supported by a Temple University

472 Graduate Fellowship.

473 
475 Aronson, M. F., C. A. Lepczyk, K. L. Evans, M. A. Goddard, S. B. Lerman, J. S. MacIvor, C. H. Nilon, and T. Vargo. 2017. Biodiversity in the city: key challenges for urban green space pollinator species traits for predicting either response to land-use change or functional

Birds of North America, editor. 2020. Cornell Lab of Ornithology, Ithaca, New York, USA.

Blair, R. B. 1996. Land use and avian species diversity along an urban gradient. Ecological

Borcard, D., F. Gillet, and P. Legendre. 2018. Canonical ordination. Pages 203-297 Numerical

Brown, A. M., D. I. Warton, N. R. Andrew, M. Binns, G. Cassis, and H. Gibb. 2014. The fourthecology with R. Springer. corner solution - using predictive models to understand how species traits interact with

Buckland, S. T., D. R. Anderson, K. P. Burnham, and J. L. Laake. 2012. Distance sampling: estimating abundance of biological populations. Springer Science \& Business Media.

491 Burkman, C. E., and M. M. Gardiner. 2014. Urban greenspace composition and landscape context influence natural enemy community composition and function. Biological Control 75:58-67.

494 Callaghan, C. T., R. E. Major, W. K. Cornwell, A. G. B. Poore, J. H. Wilshire, and M. B. Lyons. 2020. A continental measure of urbanness predicts avian response to local urbanization. Ecography 43:528-538. 
Callaghan, C. T., R. E. Major, J. H. Wilshire, J. M. Martin, R. T. Kingsford, and W. K. Cornwell. 2019. Generalists are the most urban-tolerant of birds: a phylogenetically controlled analysis of ecological and life history traits using a novel continuous measure of bird responses to urbanization. Oikos 128:845-858.

Cameron, R. W. F., P. Brindley, M. Mears, K. McEwan, F. Ferguson, D. Sheffield, A. Jorgensen, J. Riley, J. Goodrick, L. Ballard, and M. Richardson. 2020. Where the wild things are! Do urban green spaces with greater avian biodiversity promote more positive emotions in humans? Urban Ecosystems 23:301-317.

Cane, J. H., R. L. Minckley, L. J. Kervin, T. a. H. Roulston, and N. M. Williams. 2006. Complex Responses Within A Desert Bee Guild (Hymenoptera: Apiformes) To Urban Habitat Fragmentation. Ecological Applications 16:632-644.

City of Philadelphia. 2011. High Resolution Landcover, Philadelphia PA, 2008.in University of Vermont Spatial Analysis Laboratory, editor.

City of Philadelphia. 2020. Vacant Lot Program.

Cox, D. T. C., H. L. Hudson, K. E. Plummer, G. M. Siriwardena, K. Anderson, S. Hancock, P. Devine-Wright, and K. J. Gaston. 2018. Covariation in urban birds providing cultural services or disservices and people. Journal of Applied Ecology 55:2308-2319.

Cox, D. T. C., D. F. Shanahan, H. L. Hudson, K. E. Plummer, G. M. Siriwardena, R. A. Fuller, K. Anderson, S. Hancock, and K. J. Gaston. 2017. Doses of Neighborhood Nature: The Benefits for Mental Health of Living with Nature. Bioscience 67:147-155.

Daubenmire, R. F. 1959. Canopy coverage method of vegetation analysis. Northwest Science 33:39-64. 
Dennis, M., and P. James. 2017. Ecosystem services of collectively managed urban gardens:

Dickinson, D. C., and R. J. Hobbs. 2017. Cultural ecosystem services: Characteristics, challenges and lessons for urban green space research. Ecosystem services 25:179-194.

524 Donnelly, R., and J. M. Marzluff. 2004. Importance of reserve size and landscape context to urban bird conservation. Conservation Biology 18:733-745.

526 Echeverri, A., D. S. Karp, R. Naidoo, J. A. Tobias, J. Zhao, and K. M. A. Chan. 2019a. Can avian functional traits predict cultural ecosystem services? People and Nature 00:1-14.

528 Echeverri, A., R. Naidoo, D. S. Karp, K. M. A. Chan, and J. Zhao. 2019b. Iconic manakins and despicable grackles: Comparing cultural ecosystem services and disservices across

531 Ehrlich, P., D. S. Dobkin, and D. Wheye. 1988. Birder's handbook. Simon and Schuster.

532 Emad, A., and P. Bailey. 2017. wCorr: Weighted Correlations. https://CRAN.Rproject.org/package=wCorr.

534 Gardiner, M. M., C. E. Burkman, and S. P. Prajzner. 2013. The Value of Urban Vacant Land to Support Arthropod Biodiversity and Ecosystem Services. Environmental Entomology

537 Gardiner, M. M., S. P. Prajzner, C. E. Burkman, S. Albro, and P. S. Grewal. 2014. Vacant land conversion to community gardens: influences on generalist arthropod predators and biocontrol services in urban greenspaces. Urban Ecosystems 17:101-122. 
Ghanem, S. J., and C. C. Voigt. 2012. Increasing Awareness of Ecosystem Services Provided by Bats. Pages 279-302 in H. J. Brockmann, T. J. Roper, M. Naguib, J. C. Mitani, and L. W. Simmons, editors. Advances in the Study of Behavior. Academic Press.

543 Goodness, J., E. Andersson, P. M. Anderson, and T. J. E. i. Elmqvist. 2016. Exploring the links between functional traits and cultural ecosystem services to enhance urban ecosystem

Graves, R. A., S. M. Pearson, and M. G. Turner. 2019. Effects of bird community dynamics on the seasonal distribution of cultural ecosystem services. Ambio 48:280-292.

548 Haase, D., N. Larondelle, E. Andersson, M. Artmann, S. Borgström, J. Breuste, E. GomezBaggethun, Å. Gren, Z. Hamstead, and R. Hansen. 2014. A quantitative review of urban

Heckert, M., and M. Kondo. 2018. Can "cleaned and greened" lots take on the role of public Greenspace? Journal of Planning Education \& Research 38:211-221.

554 Hedblom, M., E. Heyman, H. Antonsson, and B. Gunnarsson. 2014. Bird song diversity influences young people's appreciation of urban landscapes. Urban Forestry \& Urban Greening 13:469-474.

557 Hesselbarth, M. H., M. Sciaini, K. A. With, K. Wiegand, and J. Nowosad. 2019. landscapemetrics: an open-source R tool to calculate landscape metrics. Ecography 42:1648-1657.

Jokimäki, J., J. Suhonen, and M.-L. Kaisanlahti-Jokimäki. 2018. Urban core areas are important for species conservation: A European-level analysis of breeding bird species. Landscape and Urban Planning 178:73-81. 
563 Kleyer, M. 2021. Enhancing landscape planning: Vegetation-mediated ecosystem services predicted by plant traits. Landscape and Urban Planning 215:104220.

Lavorel, S., and E. Garnier. 2002. Predicting changes in community composition and ecosystem functioning from plant traits: revisiting the Holy Grail. Functional ecology 16:545-556. solutions to the fourth-corner problem. Ecology 78:547-562. Science 2:314-320.

571 Leveau, L. M. 2013. Bird traits in urban-rural gradients: how many functional groups are there? Journal of Ornithology 154:655-662.

573 Leveau, L. M. 2022. Does spring bring colors? Seasonal bird plumage color variation along urban-rural gradients. Perspectives in Ecology and Conservation.

575 Liordos, V., J. Jokimäki, M.-L. Kaisanlahti-Jokimäki, E. Valsamidis, and V. J. Kontsiotis. 2021. Patch, matrix and disturbance variables negatively influence bird community structure in small-sized managed green spaces located in urban core areas. Science of the Total 26:27-41. Vivid colors or pattern? 13:147470491501300203.

583 Litteral, J., and E. Shochat. 2017. The role of landscape-scale factors in shaping urban bird communities. Pages 135-159 Ecology and conservation of birds in urban environments. Springer. 
Long, L. C., and S. D. Frank. 2020. Risk of bird predation and defoliating insect abundance are greater in urban forest fragments than street trees. Urban Ecosystems 23.

López-Hoffman, L., R. G. Varady, K. W. Flessa, and P. Balvanera. 2010. Ecosystem services across borders: a framework for transboundary conservation policy. Frontiers in Ecology and the Environment 8:84-91.

591 Luck, G. W., A. Carter, and L. Smallbone. 2013. Changes in bird functional diversity across multiple land uses: interpretations of functional redundancy depend on functional group identity. PLoS ONE 8.

594 Luck, G. W., S. Lavorel, S. McIntyre, and K. Lumb. 2012. Improving the application of vertebrate trait-based frameworks to the study of ecosystem services. Journal of Animal of local habitat variables and landscape context on riparian birds in agricultural,

Madureira, H., and T. Andresen. 2014. Planning for multifunctional urban green infrastructures: Promises and challenges. Urban Design International 19:38-49.

602 Manning, P., F. van der Plas, S. Soliveres, E. Allan, F. T. Maestre, G. Mace, M. J. Whittingham, and M. Fischer. 2018. Redefining ecosystem multifunctionality. Nature Ecology \& protocol.

607 Millennium Ecosystem Assessment. 2005. Millennium Ecosystem Assessment Synthesis Report. 
O’Neil-Dunne, J. 2019. Tree Canopy Assessment, Philadelphia, PA.

610 Oksanen, J., F. G. Blanchet, M. Friendly, R. Kindt, P. Legendre, D. McGlin, P. R. Minchin, R. vegan: Community Ecology Package.

Pakeman, R. J. 2011. Multivariate identification of plant functional response and effect traits in

615 an agricultural landscape. Ecology 92:1353-1365.

Pardo, L. E., M. J. Campbell, W. Edwards, G. R. Clements, and W. F. Laurance. 2018. Terrestrial mammal responses to oil palm dominated landscapes in Colombia. PLoS ONE 13:e0197539.

Pearsall, H. 2017. Staying cool in the compact city: Vacant land and urban heating in Philadelphia, Pennsylvania. Applied geography 79:84-92.

Philadelphia Parks \& Recreation. 2021. https://www.phila.gov/departments/philadelphia-parksrecreation/.

Pyle, P. 1997. Identification guide to North American birds: a compendium of information on identifying, ageing, and sexing" near-passerines" and passerines in the hand. Slate Creek Press.

R Core Team. 2015. R: A language and environment for statistical computing. R Foundation for Statistical Computing, Vienna, Austria.

Ralph, C. J., S. Droege, and J. R. Sauer. 1995. Managing and monitoring birds using point counts: standards and applications. In: Ralph, C. John; Sauer, John R.; Droege, Sam, technical editors. 1995. Monitoring bird populations by point counts. Gen. Tech. Rep. PSW-GTR-149. Albany, CA: US Department of Agriculture, Forest Service, Pacific Southwest Research Station: p. 161-168 149. 
632 Rega-Brodsky, C. C., and C. H. Nilon. 2017. Forest cover is important across multiple scales for bird communities in vacant lots. Urban Ecosystems 20:561-571.

634 Reynolds, S. J., J. D. Ibáñez Álamo, P. Sumasgutner, and M. C. Mainwaring. 2019. Urbanisation and nest building in birds: a review of threats and opportunities.

Ricklefs, R. E. 2017. Passerine morphology: external measurements of approximately onequarter of passerine bird species. 98:1472-1472. J. Pett, and S. Knapp. 2017. Understanding biodiversity-ecosystem service relationships

Sekercioglu, C. H. 2006. Increasing awareness of avian ecological function. Trends in Ecology \& Evolution 21:464-471.

643 Seto, K. C., M. Fragkias, B. Güneralp, and M. K. Reilly. 2011. A meta-analysis of global urban

645 Seto, K. C., B. Güneralp, and L. R. Hutyra. 2012. Global forecasts of urban expansion to 2030 and direct impacts on biodiversity and carbon pools. Proceedings of the National

648 South, E. C., B. C. Hohl, M. C. Kondo, J. M. MacDonald, and C. C. Branas. 2018. Effect of greening vacant land on mental health of community-dwelling adults: A cluster

651 Stachewicz, J. D., N. M. Fountain-Jones, A. Koontz, H. Woolf, W. D. Pearse, and A. S. Gallinat. 2021. Strong trait correlation and phylogenetic signal in North American ground beetle (Carabidae) morphology. Ecosphere 12:e03832. 
654 Suding, K. N., S. Lavorel, F. S. Chapin, J. H. Cornelissen, S. DIAz, E. Garnier, D. Goldberg, D.

655

656

657

658

659

660

661

662

663

664

665

666

667

668

669

670

671

672

673

674

675

U. Hooper, S. T. Jackson, and M.-L. Navas. 2008. Scaling environmental change through

the community-level: a trait-based response-and-effect framework for plants. Global Change Biology 14:1125-1140.

Ter Braak, C. J. 1986. Canonical correspondence analysis: a new eigenvector technique for multivariate direct gradient analysis. Ecology 67:1167-1179.

Threlfall, C. G., L. Mata, J. A. Mackie, A. K. Hahs, N. E. Stork, N. S. Williams, and S. J. Livesley. 2017. Increasing biodiversity in urban green spaces through simple vegetation interventions. Journal of applied ecology 54:1874-1883.

Tran, T. J., M. R. Helmus, and J. E. Behm. 2020. Green infrastructure space and traits (GIST) model: Integrating green infrastructure spatial placement and plant traits to maximize multifunctionality. Urban Forestry \& Urban Greening 49:126635.

U.S. Census Bureau. 2019. Annual Estimates of the Resident Population for Incorporated Places of 50,000 or More, Ranked by July 1, 2019 Population: April 1, 2010 to July 1, 2019.in U.S. Census Bureau, editor.

United Nations. 2018. The World's Cities in 2018- Data Booklet. UN Department of Economic and Social Affairs- Population Division.

Valencia-Aguilar, A., A. M. Cortés-Gómez, and C. A. Ruiz-Agudelo. 2013. Ecosystem services provided by amphibians and reptiles in Neotropical ecosystems. International Journal of Biodiversity Science, Ecosystem Services \& Management 9:257-272.

Valente-Neto, F., F. d. O. Roque, C. F. Pauliquevis, A. K. M. d. Oliveira, D. B. Provete, J. K. Szabo, and F. L. Souza. 2021. Loss of cultural and functional diversity associated with 
birds across the urbanization gradient in a tropical city. Frontiers in Ecology and Evolution 9:331.

678 Wang, Y., U. Naumann, S. T. Wright, and D. I. Warton. 2012. mvabund-an R package for model-based analysis of multivariate abundance data. Methods in Ecology and Evolution 3:471-474.

Warton, D. I., B. Shipley, and T. Hastie. 2015. CATS regression-a model-based approach to studying trait-based community assembly. Methods in Ecology and Evolution 6:389-398.

683 Weaving, M., J. G. White, B. Isaac, A. Rendall, and R. Cooke. 2016. Adaptation to urban environments promotes high reproductive success in the tawny frogmouth (Podargus

Whelan, C. J., D. G. Wenny, and R. J. Marquis. 2008. Ecosystem services provided by birds. Annals of the New York academy of sciences 1134:25-60.

Wilman, H., J. Belmaker, J. Simpson, C. de la Rosa, M. M. Rivadeneira, and W. J. E. Jetz. 2014. EltonTraits 1.0: Species-level foraging attributes of the world's birds and mammals: Ecological Archives E095-178. 95:2027-2027.

691 Young, R. F. 2010. Managing municipal green space for ecosystem services. Urban Forestry \& Urban Greening 9:313-321.

693 Youngsteadt, E., R. C. Henderson, A. M. Savage, A. F. Ernst, R. R. Dunn, and S. D. Frank. 2015. Habitat and species identity, not diversity, predict the extent of refuse consumption by urban arthropods. Global Change Biology 21:1103-1115. review. Oikos 125:761-768. 
bioRxiv preprint doi: https://doi.org/10.1101/2022 02 28.482331; this version posted March 2, 2022. The copyright holder for this preprint (which was not certified by peer review) is the author/funder, who has granted bioRxiv a license to display the preprint in perpetuity. It is made available under aCC-BY-NC-ND 4.0 International license.

698 Zoeller, K. C., G. G. Gurney, J. Heydinger, and G. S. Cumming. 2020. Defining cultural

699 functional groups based on perceived traits assigned to birds. Ecosystem services

$700 \quad 44: 101138$.

701 


\section{TABLES AND FIGURES}

Table 1. Habitat variables assessed for each study site.

\begin{tabular}{|c|c|c|}
\hline Scale & Variable & Description \\
\hline \multirow[t]{2}{*}{ Landscape Context } & Impervious_surf & $\begin{array}{l}\text { Proportion of impervious surface cover within } 500 \mathrm{~m} \text { of bird } \\
\text { count point }\end{array}$ \\
\hline & Tree_cover & Proportion of tree cover within $500 \mathrm{~m}$ of bird point count \\
\hline \multirow[t]{10}{*}{ Local Habitat } & Site_canopy & Site-level tree canopy cover measured by spherical densiometer \\
\hline & Shrub_stems & Density of all shrub stems per $\mathrm{m}^{2}$ \\
\hline & Tree_basalarea & Basal area of trees, scaled to site size \\
\hline & Woody_SR & Species richness of woody plants (trees and shrubs) \\
\hline & Grasses_cover & Average percent cover of grasses measured by Daubenmire class \\
\hline & Vines_cover & Average percent cover of vines measured by Daubenmire class \\
\hline & Bareground_cover & $\begin{array}{l}\text { Average percent cover of bare ground measured by Daubenmire } \\
\text { class }\end{array}$ \\
\hline & Forb_cover & Average percent cover of forbs measured by Daubenmire class \\
\hline & Veg_height & $\begin{array}{l}\text { Average height of tallest non-woody vegetation present across all } \\
\text { sampling quadrats }\end{array}$ \\
\hline & $\log$. AreaM2 & Log-transformed area of the site in $\mathrm{m}^{2}$ \\
\hline
\end{tabular}


Table 2. Descriptions and data sources for bird response and effect functional traits used to explain how local habitat and landscape context shape bird communities and ecosystem services in urban green spaces.

\begin{tabular}{|c|c|c|c|c|c|c|}
\hline $\begin{array}{l}\text { Trait } \\
\text { Family }\end{array}$ & Trait Name & $\begin{array}{l}\text { Variable } \\
\text { Type }\end{array}$ & Description & $\begin{array}{l}\text { Data } \\
\text { Source }\end{array}$ & $\begin{array}{l}\text { Response } \\
\text { Trait }\end{array}$ & $\begin{array}{l}\text { Effect } \\
\text { Trait* }\end{array}$ \\
\hline \multirow[t]{4}{*}{ Reproduction } & Clutch_Size & $\begin{array}{l}\text { Numerical, } \\
\text { Integer }\end{array}$ & $\begin{array}{l}\text { Number of eggs in a } \\
\text { clutch }\end{array}$ & 1 & $\checkmark$ & \\
\hline & Structure_nests & Binary & $\begin{array}{l}\text { Whether the species } \\
\text { nests in human-built } \\
\text { structures }\end{array}$ & 1,5 & $\checkmark$ & \\
\hline & Cavity_nests & Binary & $\begin{array}{l}\text { Whether the species } \\
\text { nests in cavities } \\
\text { (natural or human- } \\
\text { created) }\end{array}$ & 1,5 & $\checkmark$ & \\
\hline & Parental_care & $\begin{array}{l}\text { Numerical, } \\
\text { integer }\end{array}$ & $\begin{array}{l}\text { Number of days over } \\
\text { which parents } \\
\text { provide care to eggs } \\
\text { and nestlings }\end{array}$ & 1 & $\checkmark$ & \\
\hline \multirow[t]{5}{*}{ Morphology } & Body_size & $\begin{array}{l}\text { Numerical, } \\
\text { continuous }\end{array}$ & Body mass (g) & 2 & $\checkmark$ & $\mathrm{C}$ \\
\hline & Wing_length & $\begin{array}{l}\text { Numerical, } \\
\text { continuous }\end{array}$ & $\begin{array}{l}\text { Wing length relative } \\
\text { to body length (tip- } \\
\text { to-tail }[\mathrm{mm}] \text { ) }\end{array}$ & $\begin{array}{l}\text { Calculated } \\
\text { from data } \\
\text { in } 3,4,5\end{array}$ & $\checkmark$ & \\
\hline & Bill_length & $\begin{array}{l}\text { Numerical, } \\
\text { continuous }\end{array}$ & $\begin{array}{l}\text { Ratio of the bill } \\
\text { length (length of } \\
\text { culmen from the tip } \\
\text { of the upper } \\
\text { mandible to the front } \\
\text { of the skull [mm]) to } \\
\text { body length (tip-to- } \\
\text { tail [mm]) }\end{array}$ & $\begin{array}{l}\text { Calculated } \\
\text { from data } \\
\text { in } 3,4,5\end{array}$ & $\checkmark$ & $\mathrm{C}$ \\
\hline & Tail_length & $\begin{array}{l}\text { Numerical, } \\
\text { continuous }\end{array}$ & $\begin{array}{l}\text { Ratio of tail length } \\
\text { (length of the tail } \\
\text { from the base of the } \\
\text { feathers in the center } \\
\text { of the tail to the tip } \\
\text { of the longest rectrix } \\
\text { [mm]) to body length } \\
\text { (tip-to-tail [mm]) }\end{array}$ & $\begin{array}{l}\text { Calculated } \\
\text { from data } \\
\text { in } 3,4,5\end{array}$ & & $\mathrm{C}$ \\
\hline & Crest & Binary & Presence of crest & 6 & & $\mathrm{C}$ \\
\hline \multirow[t]{4}{*}{$\begin{array}{l}\text { Foraging } \\
\text { Stratum }\end{array}$} & Ground_forage & $\begin{array}{l}\text { Numerical, } \\
\text { percentage }\end{array}$ & $\begin{array}{l}\text { Proportion of } \\
\text { foraging time spent } \\
\text { on ground }\end{array}$ & 2 & $\checkmark$ & \\
\hline & ForStrat_midhigh & $\begin{array}{l}\text { Numerical, } \\
\text { percentage }\end{array}$ & $\begin{array}{l}\text { Proportion of } \\
\text { foraging time spent } \\
<2 \mathrm{~m}\end{array}$ & 2 & $\checkmark$ & \\
\hline & ForStrat_understory & $\begin{array}{l}\text { Numerical, } \\
\text { percentage }\end{array}$ & $\begin{array}{l}\text { Proportion of } \\
\text { foraging time spent } \\
2 \mathrm{~m} \text { to canopy }\end{array}$ & 2 & $\checkmark$ & \\
\hline & Canopy_forage & $\begin{array}{l}\text { Numerical, } \\
\text { percentage }\end{array}$ & $\begin{array}{l}\text { Proportion of } \\
\text { foraging time spent } \\
\text { in canopy }\end{array}$ & 2 & $\checkmark$ & \\
\hline $\begin{array}{l}\text { Diet } \\
\text { Preference }\end{array}$ & Diet_generality & $\begin{array}{l}\text { Numerical, } \\
\text { continuous }\end{array}$ & $\begin{array}{l}\text { Shannon evenness of } \\
\text { diet across all diet } \\
\text { categories }\end{array}$ & $\begin{array}{l}\text { Calculated } \\
\text { from data } \\
\text { in } 2\end{array}$ & $\checkmark$ & $\mathrm{R}$ \\
\hline
\end{tabular}




\begin{tabular}{|c|c|c|c|c|c|c|}
\hline & Invertebrates & $\begin{array}{l}\text { Numerical, } \\
\text { percentage }\end{array}$ & $\begin{array}{l}\text { Proportion of diet } \\
\text { consisting of } \\
\text { invertebrates }\end{array}$ & 2 & $\checkmark$ & $\mathrm{R}$ \\
\hline & Seeds & $\begin{array}{l}\text { Numerical, } \\
\text { percentage }\end{array}$ & $\begin{array}{l}\text { Proportion of diet } \\
\text { consisting of seeds }\end{array}$ & 2 & $\checkmark$ & $\mathrm{R}$ \\
\hline & Fruits & $\begin{array}{l}\text { Numerical, } \\
\text { percentage }\end{array}$ & $\begin{array}{l}\text { Proportion of diet } \\
\text { consisting of fruits }\end{array}$ & 2 & $\checkmark$ & $\mathrm{R}$ \\
\hline & Plans & $\begin{array}{l}\text { Numerical, } \\
\text { percentage }\end{array}$ & $\begin{array}{l}\text { Proportion of diet } \\
\text { consisting of plant } \\
\text { material other than } \\
\text { seeds or fruit }\end{array}$ & 2 & $\checkmark$ & \\
\hline \multirow[t]{2}{*}{ Acoustic } & Syllable_count & $\begin{array}{l}\text { Numerical, } \\
\text { integer }\end{array}$ & $\begin{array}{l}\text { Number of unique } \\
\text { syllables in a typical } \\
\text { song or call }\end{array}$ & 6 & & $\mathrm{C}$ \\
\hline & Delta_frequency & $\begin{array}{l}\text { Numerical, } \\
\text { continuous }\end{array}$ & $\begin{array}{l}\text { Mean difference in } \\
\text { Hz between the } \\
\text { highest and lowest } \\
\text { frequency of each } \\
\text { syllable in the song }\end{array}$ & 6 & & $\mathrm{C}$ \\
\hline \multirow[t]{4}{*}{ Plumage } & Cool_plumage & Binary & $\begin{array}{l}\text { Blue, purple, or } \\
\text { green hues are } \\
\text { predominant colors } \\
\text { (>50\% of body } \\
\text { surface area) }\end{array}$ & 6 & & $\mathrm{C}$ \\
\hline & Warm_plumage & Binary & $\begin{array}{l}\text { Red, yellow, or } \\
\text { orange are } \\
\text { predominant colors }\end{array}$ & 6 & & $\mathrm{C}$ \\
\hline & Dull_plumage & Binary & $\begin{array}{l}\text { Gray, brown, tan, or } \\
\text { beige are } \\
\text { predominant colors }\end{array}$ & 6 & & $\mathrm{C}$ \\
\hline & Black_plumage & Binary & $\begin{array}{l}\text { Black is predominant } \\
\text { color }\end{array}$ & 6 & & $\mathrm{C}$ \\
\hline
\end{tabular}

\footnotetext{
${ }^{1}$ Ehrlich et al. (1988) ${ }^{2}$ Wilman et al. (2014) ${ }^{3}$ Pyle (1997) ${ }^{4}$ (Ricklefs 2017) ${ }^{5}$ Birds of North America (2020)
}

${ }^{6}$ Collected for this study; ${ }^{*} \mathrm{C}=$ Cultural ecosystem service, $\mathrm{R}=$ Regulating ecosystem service 
Figure 1. Tile plot indicating the direction and strength of interaction coefficients between avian response traits and landscape context (Impervious_surf and Tree_cover) and local habitat (PC1.Woody and PC2.Herbaceous) variables from multiple linear regression modeling. Interactions without sufficient statistical support appear as blank tiles. Black boxes highlight the strongest response trait-environmental variable interactions (magnitude of coefficients in the $95^{\text {th }}$ percentile across all variables).

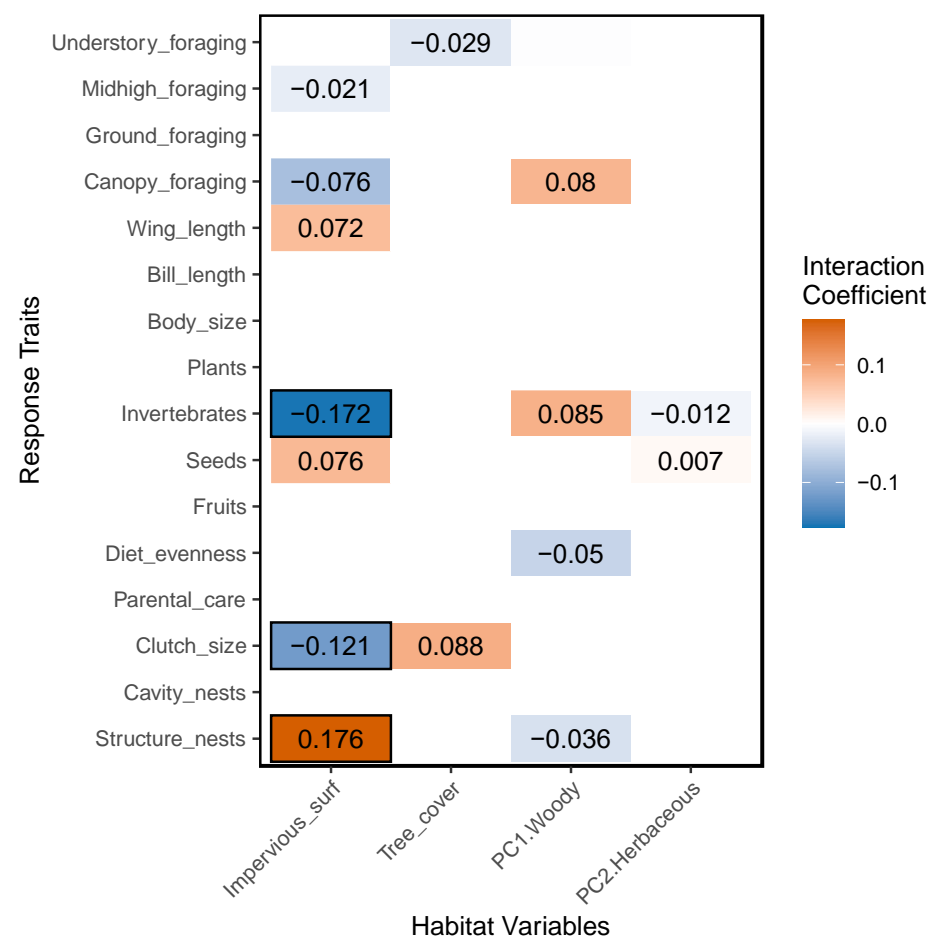


Figure 2. Tile plots of pairwise abundance-weighted Pearson correlations between avian response and effect traits, grouped by effect trait family. Acoustic, plumage, and shape families contribute to cultural ecosystem services whereas diet traits contribute to regulating services. Significant correlations (alpha $=0.05)$ are outlined with a black border.

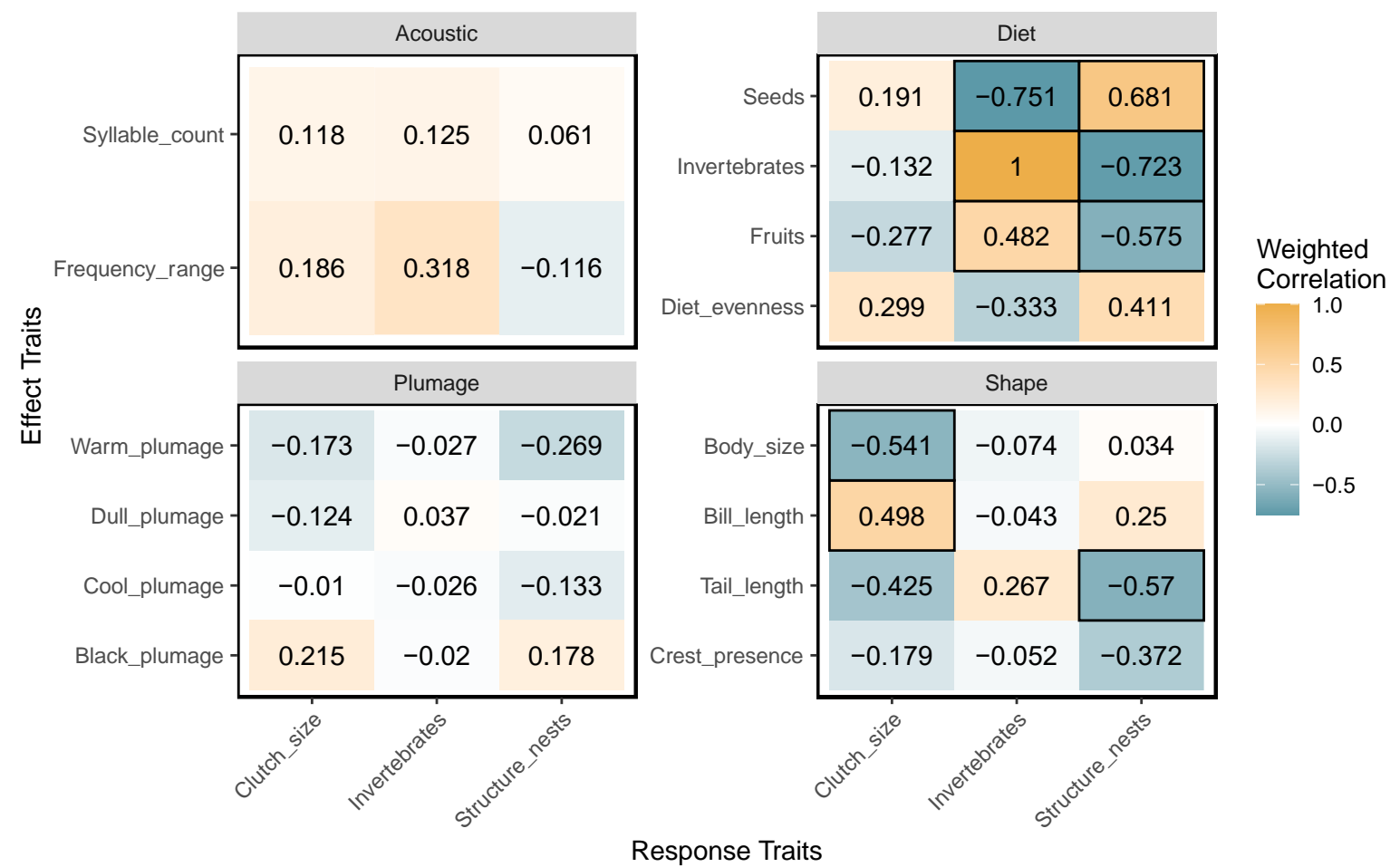


Figure 3. Redundancy analysis (RDA) biplot showing the centroids of avian effect traits as explained by environmental variables (vector arrows, bold text). Effect traits are grouped by the ecosystem service to which they contribute (symbol and color) as well as the direction of their contribution to the service (positive or negative, see Table S3). Note, RDA axes displayed on different scales.

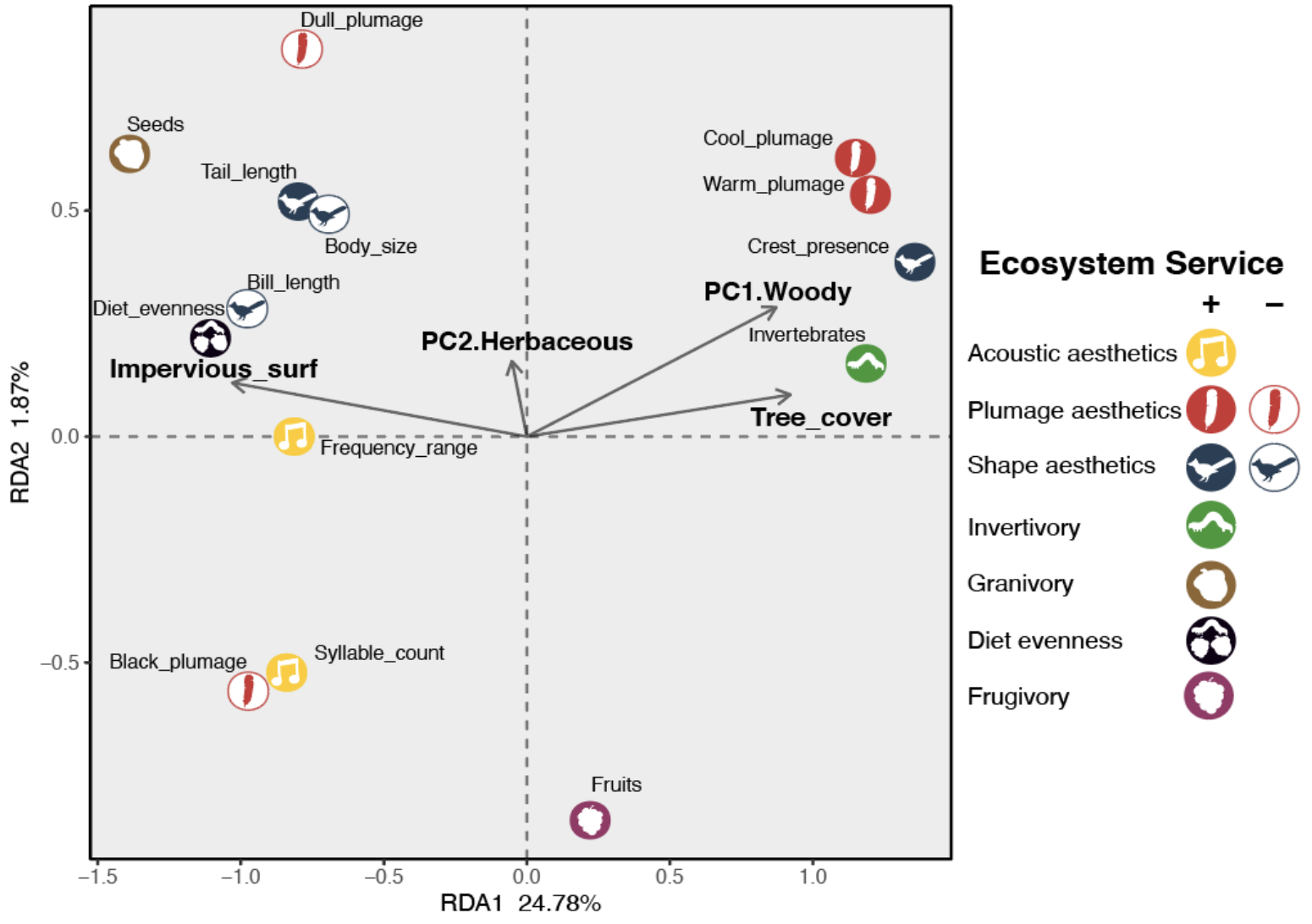


Figure 4. Plots depicting the effect of four local and landscape habitat variables on 7 ecosystem service scores. Standardized model coefficients and 95\% confidence intervals from linear regression models are displayed, filled circles denote statistically significant coefficient (alpha $=0.007)$.

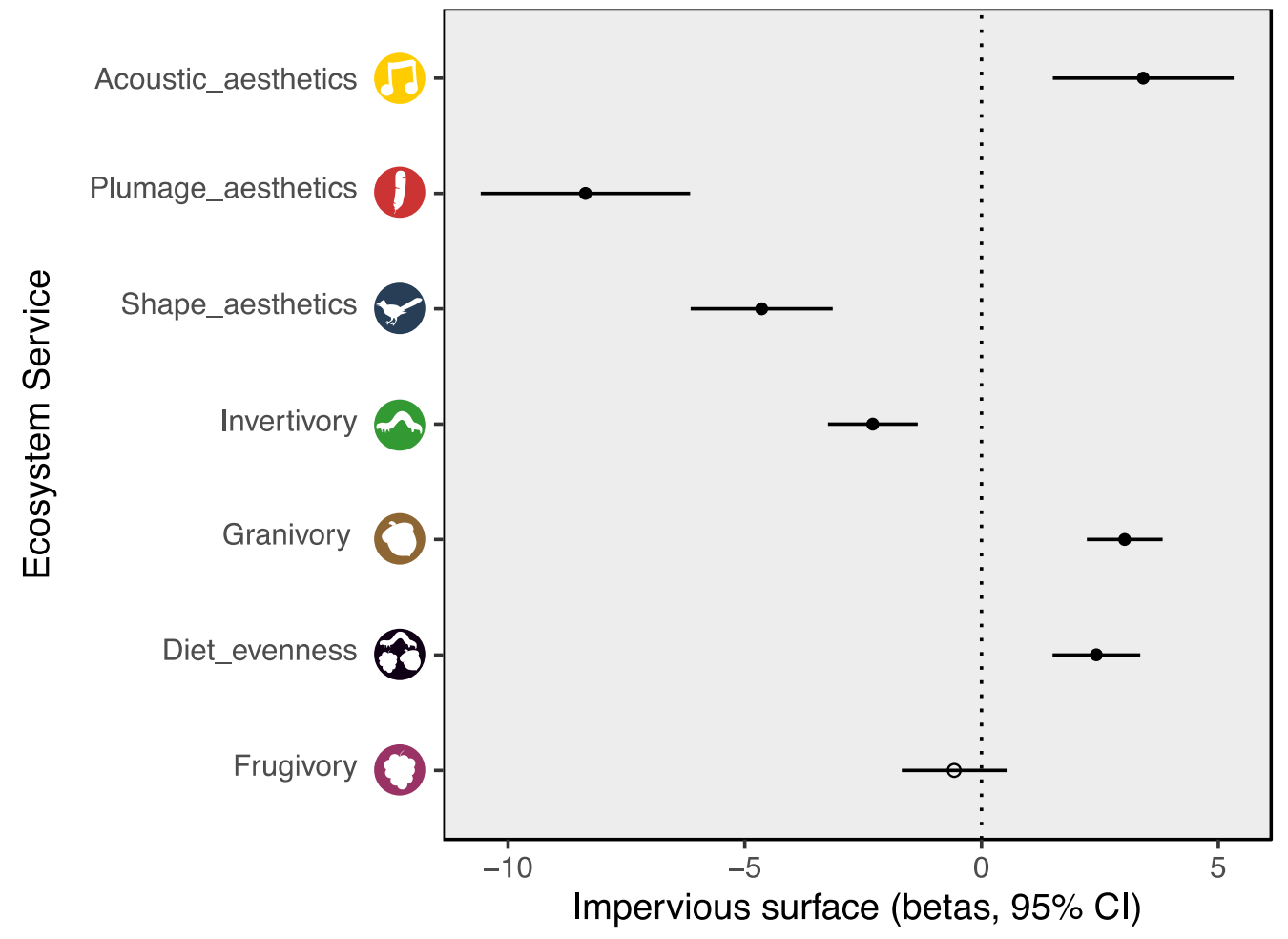

